\title{
Factors influencing attitudes and intentions towards smart retail technology
}

\author{
Selvan Perumal ${ }^{a *}$, Yeoh Rong Qing ${ }^{\mathrm{b}}$ and Mathivannan Jaganathan ${ }^{\mathrm{a}}$
}

${ }^{a}$ School of Business Management, College of Business, Universiti Utara Malaysia, Malaysia ${ }^{b}$ Phd Scholar, School of Business Management, College of Business, Universiti Utara Malaysia, Malaysia

\section{H R O N I C L E}

Article history:

Received: June 29, 2021

Received in revised format: September 29, 2021

Accepted: November 8, 2021

Available online: November 9 , 2021

Keywords:

Smart Retail Technology (SRT)

Technology Acceptance Model (TAM)

Brick-and-mortar stores

\section{Introduction}

Nowadays, the building concept of the Internet of Things is bounded in many industries. One industry research has shown that the IoT market achieved 15.4 billion installed devices in the last year. It will grow from 30.7 billion installed devices in 2020 to 75.4 billion in 2025 (IHS, 2016). It will bring each other closer in the physical environment and allow people to have high interconnectivity in daily lives. However, such a vision must get support through favorable policies from the government. For example, the Malaysian government recently introduced the Malaysia Smart Cities Framework to track global urban development trends (MAMPU, 2021). With the support of seven components, namely, Smart Economy, Smart Living, Smart Environment, Smart People, Smart Government, Smart Mobility, and Smart Digital Infrastructure, the government will produce a sustainable environment that can upsurge quality of life among citizens (MAMPU, 2021). The Budget 2020 also demonstrates that the government strengthens the digital industry and moves local businesses into the technology domain (New Straits Times, 2019). Therefore, the ever-changing technology landscape is challenging the existing status quo. As one of the subsets of smart city, "Smart Retail Technology" (hereafter, SRT) is a central integrated retail system that can connect different in-store touchpoints to provide highly responsive retail services when customers patronage brick-and-mortar retail stores (Roy, et al., 2017). Retailing to become smarter than ever is the next milestone that needs to be achieved by brick-andmortar retailers as soon as possible. SRT involves technologies or touchpoints such as smart mirrors, radio frequency identification, smart kiosks, smart price tags, facial recognition, smart shelves, smart carts, unmanned shops, smart fitting rooms, shelf-checkout counters and many other ongoing inventions. The SRT merges physical and digital dimensions into a shopping

* Corresponding author

E-mail address: selvan@uum.edu.my (S. Perumal)

(C) 2022 by the authors; licensee Growing Science, Canada. doi: $10.5267 / j . i j d n s .2021 .11 .005$ 
location (Kim, et al., 2017). This represents that customer can enjoy more personalised in-store shopping experiences as supporting such building blocks becomes a single body ( $\mathrm{Ng}$, et al., 2019).

SRT started expanding in foreign countries, such as China (Chang et al., 2021), Australia (Roy et al., 2021; Roy, et al., 2020) and the United States (Newman, et al., 2018). Correspondingly, Malaysia also adopts and at the beginning stage in the SRT development progress (Rahman et al., 2020; Ng, et al., 2019). Integrating SRT in the brick-and-mortar shopping mode and providing customers with opportunities for enjoying a smarter retail experience when shopping is the main task of retailers. Of the study conducted by Roy et al. (2018), five cognitive variables had been included, and they recommended that future research include non-cognitive variables to explore further the influence of other aspects on customer's behavioural intention towards SRT. Perceived enjoyment is included to explore how using SRT can create joyfulness in customers' shopping journeys. Many businesses or industries are incrementally focusing on customers' return on experience (ROX), especially the high human-interaction shopping process (PwC, 2019). This study also recommended researching developing countries such as India, Malaysia, and China to deepen the domain of SRT (Roy et al., 2018). In Malaysia, there are still large areas to explore SRT from different perspectives ( $\mathrm{Ng}$ et al., 2019). Noticeably, the domain of SRT provided a fertile area for the researcher to examine its influence on customers further.

This study examines the influence of cognitive and non-cognitive factors on customers' attitudes and behavioural intentions towards SRT among Malaysian customers. As the alternative solution to physical retailing, SRT must inherit usefulness characteristics to ensure customers can maintain themselves as long-term users. Due to the notion that using SRT is still infant, the researchers are unclear about how perceived usefulness and ease of use play their roles when customers use SRT. The unknown situation also leaves customers with the risk concern due to omitting some service employees and the SRT performance creates challenging customers. Likewise, different countries' customers have perceptions of a particular technology, and the extant literature urged further expanding such study into other countries or areas (Adapa et al., 2020; Roy et al., 2018). The extent of Malaysians' attitudes and behavioural intentions towards SRT are imperative to determine whether the bundle of smart retail touchpoints can succeed in the local marketplace. Furthermore, customers' intentions approximately predict real behaviours. In addition, some researchers only studied certain age groups towards SRT in Malaysia (Ng et al., 2019). This implies the preceding study had not provided generalizability in the SRT literature from the Malaysia perspective. For the stated reasons, the study is very imperative because consumers' positive attitude encouraged consumers' behavioural intentions toward SRT in the upcoming retail landscape (Adapa et al., 2020).

\section{Theoretical Background}

\subsection{The Concept of Smart Retail Technology (SRT)}

Smart retail technology (SRT) is the central connection system between smart and intelligent devices that can produce high interactive retail services to deliver personalised and effective in-store shopping experiences to customers (Wünderlich et al., 2015). By integrating AI algorithms, the intelligent touchpoints applied by brick-and-mortar retailers can manipulate SRT devices to achieve several functions such as sense the real-time retail environment inside the physical retail stores, real-time data collection, and recommend offerings to replace the roles of humans to communicate with customers. SRT also improves shopping flexibility that can accustom customers to shop in brick-and-mortar retail stores (Roy et al., 2017). This implies the SRT is highly dependent on the synergy among the in-store touchpoints. Moreover, the 'cooperation between front-end and back-end operations are crucial to provide the real value proposition by retailers to customers when customer patronage in the brick-and-mortar stores (Kim, et al., 2016). Various studies have been conducted to explore the development progress of SRT from the customer perspective. For instance, the customer's loyalty towards SRT was studied (Adapa et al. 2020), cognitive enablers to yield customers' attitudes and behavioural intention towards SRT was conducted in Australia (Roy, et al., 2018) or even studied customers' shopping intentions and engagement in the research background of unmanned retail stores. In Malaysia, the noticeable SRT literature was conducted among Generation-Z with three enablers: perceived usefulness, perceived value, and enjoyment to influence that customer group to spread word-of-mouth ( $\mathrm{Ng}$, et al., 2019). However, some scarcities were left by those researchers allowing more SRT studies to be conducted in Malaysia. Indeed, SRT is a great milestone for the existing brick-and-mortar retailers to increase their business flexibility, customisation and reduced business costs (Adapa et al., 2020). It will let customers get better value since they are ready to adopt it in physical retail stores. In response to the recommendations by Roy et al. (2018), Adapa et al. (2020) and Kasilingam (2020), the researchers conducted the research in Malaysia, which is the country at the infant stage in the development of SRT.

\subsection{Technology Acceptance Model}

There is no theory to fit all conditions of technological studies and understand how people approach every new technology (Straub, 2009). Technology Acceptance Model (hereafter, TAM) is the broadest acceptable theory that researchers use (Pillai, et al., 2020). Originally, TAM was presented in the study of technology users' initial acceptance or adoption of technological innovation (Davis, 1989). It explained the linkages of beliefs-attitude-intention-we called the people's process to get used to technology innovation (Kim et, al., 2017). It has two exogenous variables, and two endogenous variables were widely applied in various studies. Perceived usefulness is the belief regarding how customers achieve their performance by using technology. Perceived ease of use means the people's beliefs using technology would be free of effort. Attitude is about how customers 
feel that technology is favourable or unfavourable, while the behavioural intention is the proxy of customers' behaviour (Patil, et al., 2020; Davis, 1989).

Previous studies have proved the Technology Acceptance Model to examine electronic banking services. As such, Salihu et. al. (2019) applied the TAM theory to explore the variables that can arise from electronic banking issues. They found that security and ease-of-use have a negative relationship with the issues of electronic banking. In addition, the study of Li et al., (2017) deployed the extended TAM to examine consumers' attitudes towards e-auctions. The results indicated that perceived usefulness and ease of use positively influence consumers' attitudes towards the e-auctions system. Furthermore, the study of Cakır and Solak (2015) used the TAM theory as also indicated that TAM variables have a significant effect on the Turkish elearner's academic achievement. In the retail domain, some preceding studies adapted TAM with some other variables to examine the consumers' acceptance of retail technologies (Yan et al., 2021; Pilllai et al., 2020; Roy et al., 2018; Pantano et al., 2017; Kim et al., 2017; Roy, et al., 2017; Kaushik and Rahman, 2015). Although TAM has experienced three decades in many technology-relevant works of literature, the theory is still performing its academic influence to identify people's readiness to accept and adopt contemporary technologies in different domains.

\section{Hypotheses Development}

\subsection{Effect of Perceived Usefulness on Attitudes}

According to Davis (1985), perceived usefulness (PU) can be defined as "the degree to which a person believes that using a particular system would boost their job performance." The researchers defined perceived usefulness as the degree to which a person perceives that using SRT would boost their job or personal performance. The utility benefit given to customers will enhance their willingness to use a technology innovation (Kazancoglu \& Yarimoglu, 2017). Within the retail context, since Malaysia is still at the infant stage in terms of IoT development, the retailers should create consumers' awareness about the greatness of SRT and inform the non-adopters how their current performance will be boosted up by using SRT and achieve high productivity when SRT play roles in their shopping journey in the brick-and-mortar retail stores.

Until now, the influence of perceived usefulness on technology users' attitude has been confirmed in various extant literature. For instance, Roy et al. (2018) have confirmed that the relationship between perceived usefulness and attitude was significant among Australia' SRT users. A similar outcome has also resulted in the local SRT study among Generation- $\mathrm{Z}$ customers (Ng et al., 2019). Likewise, the significant relationship also happened in the study of AR-retail apps (Bonetti et al., 2018), virtual try-on smart mirrors (Pantano et al., 2017) and mobile payment (Patil et al., 2020). Thus, the researchers postulate the first hypothesis as follows:

\section{$\mathbf{H}_{1}$ : Perceived usefulness influences the consumers' attitudes towards SRT.}

\subsection{Effect of Perceived Ease of Use on Attitudes}

The meaning of perceived ease of use was adapted from the original literature for the SRT context (Davis, 1989). It can be defined as the functions of SRT are user-friendly, high understandable interfaces, low complexity of operating procedures and low learning effort for the innovations. Customers can get effortless shopping experience by using SRT is another important reason to arise in many studies in the domain of retailing (Liang et al., 2019; Roy et al., 2018; Kim et al., 2017; Li et al., 2017; Wu et al., 2016; Kaushik \& Rahman, 2015). By the supporting of extant literature, the researchers postulate perceived ease of use has a significant relationship to attitude as the following statement:

\section{$\mathbf{H}_{2}$ : Perceived ease of use influences the consumers' attitudes towards SRT.}

\subsection{Effect of Perceived Enjoyment on Attitudes}

This study adopted the definition from (Dickinger et al., 2008) to define perceived enjoyment as the degree to which a person perceives using SRT as an enjoyable activity apart from any anticipated consequence derived from the particular technologies' performance. By shaping the customer's perceived enjoyment, SRT provides them with personalised retail services, fun, and convenience and has a good interaction between humans and machines that can increase customers' curiosity to explore SRT. This implies that customers' perceived enjoyment is an emotional component when using SRT without considering the performance characteristics. Consumers' perceived enjoyment influences the acceptance of technological innovations (Adapa et al., 2020). According to the study of Choi and Kim (2016), enjoyment was a strong determinant that moves consumers' behaviour towards smart technologies in fashion retail stores. Unlike traditional physical retailing, SRT provides personalised retail services, increases consumers' control of the shopping process, and improves shopping convenience and derives shopping enjoyment (Roy et al., 2018). In line with the previous studies, the researchers postulate the hypothesis as follows:

\section{H3: Perceived enjoyment influences the consumers' attitudes towards SRT.}

\subsection{Effect of Perceived Risk on Attitudes}

Perceived risk can be defined as the task-related problems that drive users to feel uncertain, concerned, discomfort, and anxious, moving users apart from using SRT (Featherman \& Pavlou, 2003). In the step of technology introduction, retailers should 
mitigate the magnitude of risk association and enhance the customers' confidence towards SRT (Adapa, et al., 2020). Retailers should uncover the potential issues that can hinder customers from accepting and adopting SRT. For instance, customers do not be uncertain when retailers explicitly promise the personal data is secured. This implies risk is the trade-off between people who believe they have a high capability to overcome the uncertainty when using SRT.

Perceived risk has been proven in the research of India's internet banking context. It has a negative outcome and creates uncertainty for technology users. The more consumers distrust internet banking, the more perceived risk and a negative attitude arise (Bashir \& Madhavaiah, 2017). The high perceived risk created uncertainty in consumers' minds since they were unwilling to bear any worse consequences after using a particular technology. The more consumers distrust internet banking, the more perceived risk and negative attitudes arise (Bashir \& Madhavaiah, 2017). According to the study run by Adapa et al. (2020), consumers' perceptions about the risk associated with technological innovation may steer consumers away from adopting it after getting dissatisfaction. From the preceding literature, the researchers hypothesise perceived risk influence customers' attitudes towards SRT.

\section{$\mathbf{H}_{4}$ : Perceived risk influences the consumers' attitudes towards SRT.}

\subsection{Effect of Attitudes on Behavioural Intentions}

Attitude can be defined as the individual's positive or negative evaluation of performing a particular behaviour. Positive or optimistic attitudes always positively impacted the customers' behaviours (Ajzen \& Fishbein, 1980). Shortly, it is related to how customers feel that technology is favourable or unfavourable and imperative when customers initially accept or adopt new technology (Adapa et al., 2020). The affective construct represents user assessment of the information system to decide whether to form positive behavioural intentions towards a new technology (Pantano et al., 2017). Chronologically, attitude towards smart in-store technologies has been proven by the study of Kim et al. (2017), which fully mediated the three pre-set technologies' features to consumers' behavioural intentions toward smart in-store technologies. According to Liang et al. (2019), attitude towards Amazon's Echo Look was crucial in influencing the customers' purchase intention. A similar relationship also has been validated in the study of customers' cognitive variables towards SRT in Australia (Roy et al., 2020; Roy et al. 2018), e-commerce chatbots (Kasilingam, 2020) and self-service technologies (Park \& Jeong 2020). Hence, the researcher postulated the relationship between attitudes and behavioural intentions as below:

\section{H5: Consumers' attitudes towards SRT influence the consumers' behavioural intentions of using SRT.}

\subsection{The Mediating Effects of Attitudes}

Attitude is the degree of evaluative effect performed by customers towards SRT. The researcher suggested that positive attitudes were a good linkage between customers' perceptions and behavioural intentions towards SRT. When a positive attitude arises, customers have a favourable educated inclination to evaluate new technology. It has been proven the mediating role of attitude in extant literature. This contention is in line with the study conducted by $\mathrm{Ng}$ et al. (2019), which showed that the perceived usefulness and enjoyment had influenced the word-of-mouth of the Malaysia Generation-Z customers toward SRT with a mediation effect of attitude. Similarly, performance expectancy mediated by attitude towards SRT indirectly influences customer engagement behaviour, but effort expectancy had no indirect effect. The results were partially similar in the study conducted by Kasilingam (2020), indicating that attitude mediates perceived usefulness, ease of use, enjoyment, and risk to influence the Indian customers' intentions to use smartphone chatbots in mobile shopping. Among the variables involved, perceived risk has hindered the customers in using the mobile shopping's chatbots. However, the SRT does not solely focus on the nature of online shopping but also involves traditional retailing. Saying another way, SRT may involve immobile, mobile, and hybrid systems in brick-and-mortar stores (Pantano \& Viassone, 2014). Hence, the researchers expand such a study to the SRT context in Malaysia. The indirect effect of attitudes towards SRT play as the mediator among customers' perceptions and behavioural intentions towards SRT has been hypothesised as the following:

H6: Consumer attitudes towards SRT mediate the relationship between perceived usefulness and behavioural intentions of using SRT.

$\mathbf{H}_{7}$ : Consumer attitudes towards SRT mediate the relationship between perceived ease of use and behavioural intentions of using SRT.

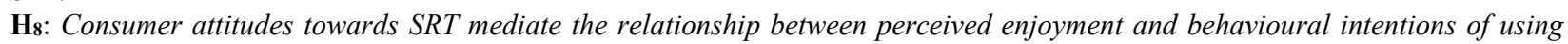
SRT

H9: Consumer attitudes towards SRT mediate the relationship between perceived risk and behavioural intentions of using SRT.

\section{Research Methodology}

This study adopted the quantitative research approach to determine the relationships among customers' perceptions, attitudes, and behavioural intentions towards SRT. Due to the pandemic of Covid-19 and the society was required to strictly follow the movement control order, the researchers have designed an online self-administered questionnaire to answer the target respondents, the persons who have used any SRT in the area of Klang Valley. The researchers applied a 5-point Likert scale to examine the main body of the questionnaire: perceived usefulness, perceived ease of use, perceived enjoyment, perceived 
risk, attitudes towards SRT, and behavioural intentions towards SRT. The four and six items of perceived usefulness and perceived ease of use, respectively, were adapted from Davis (1989). While five items for perceived enjoyment were measured by the items of Wang and Li (2012) and the researcher adapted the perceived risk's items from Kazancoglu and Yarimoglu (2017). Attitudes and behavioural intentions towards SRT were measured using the items previously used by Liu et al. (2017) and Gao and Bai (2014). After assigning 481 questionnaires, the researchers received 170 valid samples or accounted for 43.66 percent of the response rate, which considered achieve the bottom line of partial least study (Kock \& Hadaya, 2018).

\section{Results}

\subsection{Measurement Model}

The main information in the measurement model, namely, constructs' reliability, convergent validity, and discriminant validity (Roy, et al., 2021). According to the suggestions by Hair et al. (2017): the composite reliability and rho_A must be equal or greater than 0.7 . As well, Cronbach's alpha also must be equal to or greater than 0.7 . The value of Cronbach's alpha is generally smaller than composite reliability. Subsequently, the loadings and the AVE values should be equal or greater than 0.5, respectively (Lam, 2012; Fornell \& Larcker, 1981).

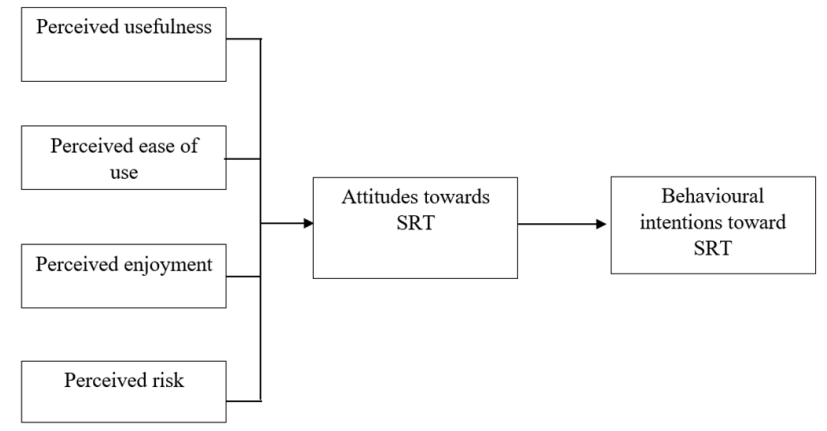

Table 1

Fig. 1. Research framework

Measurement model

\begin{tabular}{|c|c|c|c|c|c|c|}
\hline Latent variable & Items & Loadings & Cronbach's alpha & rho_A & $\begin{array}{l}\text { Average } \\
\text { Variance }\end{array}$ & $\begin{array}{l}\text { Composite } \\
\text { Reliability }\end{array}$ \\
\hline \multirow{4}{*}{ Perceived usefulness } & PU1 & 0.892 & 0.785 & 0.903 & 0.580 & 0.843 \\
\hline & PU2 & 0.553 & & & & \\
\hline & PU3 & 0.849 & & & & \\
\hline & PU4 & 0.707 & & & & \\
\hline \multirow{6}{*}{ Perceived ease of use } & PEOU1 & 0.593 & 0.765 & 0.771 & 0.458 & 0.834 \\
\hline & PEOU2 & 0.731 & & & & \\
\hline & PEOU3 & 0.716 & & & & \\
\hline & PEOU4 & 0.735 & & & & \\
\hline & PEOU5 & 0.676 & & & & \\
\hline & PEOU6 & 0.591 & & & & \\
\hline \multirow{5}{*}{ Perceived enjoyment } & tPE1 & Deleted & 0.776 & 0.829 & 0.590 & 0.851 \\
\hline & PE2 & 0.815 & & & & \\
\hline & PE3 & 0.748 & & & & \\
\hline & PE4 & 0.786 & & & & \\
\hline & PE5 & 0.706 & & & & \\
\hline \multirow{5}{*}{ Perceived risk } & tPR1 & Deleted & 0.742 & 0.907 & 0.644 & 0.843 \\
\hline & PR2 & 0.611 & & & & \\
\hline & PR3 & 0.521 & & & & \\
\hline & PR4 & 0.503 & & & & \\
\hline & tPR5 & Deleted & & & & \\
\hline \multirow{3}{*}{ Attitudes towards SRT } & ATD1 & 0.835 & 0.765 & 0.767 & 0.680 & 0.864 \\
\hline & ATD2 & 0.785 & & & & \\
\hline & ATD3 & 0.852 & & & & \\
\hline \multirow{5}{*}{ Behavioral intentions towards SRT } & BI1 & 0.839 & 0.833 & 0.842 & 0.599 & 0.882 \\
\hline & $\mathrm{BI} 2$ & 0.710 & & & & \\
\hline & $\mathrm{BI} 3$ & 0.771 & & & & \\
\hline & $\mathrm{BI} 4$ & 0.793 & & & & \\
\hline & BI5 & 0.751 & & & & \\
\hline
\end{tabular}

Subsequently, the initial running of PLS-SEM resulted in three items being deleted (PE1, PR1, and PR5) because the loading values were below than 0.5 . Removing the low loading items establishes reasonable reliability and convergent validity (Ng et al., 2019; Rasoolimanesh et al., 2018; Hair et al., 2017). Subsequently, the researchers obtained composite results ranging from 0.834 to 0.852 , surpassing the threshold value 0.7 , and the researcher has obtained a satisfactory value. The satisfactory results have been shown in Cronbach's alpha column. All variables achieved 0.5, except perceived ease of use. The average 
variance extracted falls below than 0.5 , which ranges between 0.31 and 0.4 , still has adequate convergent validity and it can be accepted if the adequate level of composite reliability (Lam, 2012; Fornell \& Larcker, 1981).

\subsection{Structural Model}

For the next step, this research has undergone the PLS-SEM bootstrapping resample procedure to test the significance level and path coefficient, including direct and indirect relationships (Hair et al., 2017).

\section{Table 2}

Structural model

\begin{tabular}{|c|c|c|c|c|c|c|c|c|c|}
\hline Hypothesis & Path & $\begin{array}{l}\text { Direct } \\
\text { effect }\end{array}$ & Indirect effect & S.D. & $\mathrm{F} 2$ & VIF & T-value & P-value & Decision \\
\hline H1 & $\mathrm{PU} \rightarrow \mathrm{ATD}$ & 0.066 & & 0.114 & $0.007(\mathrm{~T})$ & 1.048 & 0.583 & 0.560 & Rejected \\
\hline H2 & $\mathrm{P}$ E O U $\rightarrow$ ATD & 0.276 & & 0.069 & $0.161(\mathrm{M})$ & 1.022 & 4.021 & 0.000 & Supported \\
\hline H3 & $\mathrm{PE} \rightarrow \mathrm{ATD}$ & 0.223 & & 0.061 & $0.096(\mathrm{~S})$ & 1.022 & 3.666 & 0.000 & Supported \\
\hline H4 & $\mathrm{PR} \rightarrow \mathrm{ATD}$ & -0.105 & & 0.086 & $0.023(\mathrm{~S})$ & 1.023 & 1.222 & 0.222 & Rejected \\
\hline H5 & $\mathrm{ATD} \rightarrow \mathrm{BI}$ & 0.221 & & 0.069 & $0.082(\mathrm{~S})$ & 1.000 & 3.225 & 0.001 & Supported \\
\hline H6 & $\mathrm{PU} \rightarrow \mathrm{ATD} \rightarrow \mathrm{BI}$ & & 0.015 & 0.028 & & & 0.526 & 0.599 & Rejected \\
\hline H7 & $\mathrm{P}$ E O U $\rightarrow$ ATD $\rightarrow$ BI & & 0.061 & 0.033 & & & 1.868 & 0.062 & Supported \\
\hline H8 & $\mathrm{PE} \rightarrow \mathrm{ATD} \rightarrow \mathrm{BI}$ & & 0.049 & 0.020 & & & 2.412 & 0.016 & Supported \\
\hline H9 & $\mathrm{PR} \rightarrow \mathrm{ATD} \rightarrow \mathrm{BI}$ & & -0.023 & 0.023 & & & 1.023 & 0.307 & Rejected \\
\hline
\end{tabular}

The path coefficient, T-value and p-value of every direct and indirect relationship were measured in Table 2 . The result showed that perceived usefulness insignificantly influences customers' attitudes towards SRT $(\beta=0.066, t=0.583, p=0.560)$ and $\mathrm{H} 1$ was rejected. However, the relationships between perceived ease of use and attitudes towards SRT $(\beta=0.276, \mathrm{t}=$ $4.021, \mathrm{p}<0.001$ ) have rejected the null hypothesis and implied it has an association. Thus, H3 was supported. Likewise, the relationship between perceived enjoyment and attitudes towards SRT (H3) also supported $(\beta=0.223, t=3.666, p<0.001)$. Conversely, $\mathrm{H} 4$ was not supported, as the impact of perceived risk on attitudes towards SRT shown insignificant relationship $(\beta=-1.05, t=1.222, p=0.222)$ while the customers' attitudes impact on the behavioural intentions towards SRT $(\beta=0.221$, $\mathrm{t}=3.225, \mathrm{p}<0.001)$, H5 was supported. Additionally, the customers' attitudes towards SRT significantly mediate perceived ease of use $(\beta=0.061, t=1.868, p=0.062)$ and perceived enjoyment $(\beta=0.049, t=2.412, p=0.016)$ to influence behavioural intentions, $\mathrm{H} 7$ and $\mathrm{H} 8$ were supported. The confidence level of $90 \%$ and 0.1 minimum significance level were adopted to support the mediating relationship in the seventh hypothesis (Kasilingam, 2020). H6 and H9 were rejected as the attitudes significantly mediate the relationship between perceived usefulness and behavioural intentions $(\beta=0.015, \mathrm{t}=0.526, \mathrm{p}=$ $0.599)$ as well as perceived risk and behavioural intentions $(\beta=0.023, \mathrm{t}=1.023, \mathrm{p}=0.307)$.

\section{Discussions}

This study aimed to examine the direct effect of perceived usefulness, perceived ease of use, perceived enjoyment and perceived risk on the customers' attitudes towards SRT. Additionally, this study investigates the mediating effect of attitudes towards SRT on the relationships between perceived usefulness, ease of use, enjoyment, and risk and behavioural intentions towards SRT. Conclusion this study resulted in the conclusion that perceived usefulness insignificantly influences attitudes towards SRT, which is inconsistent with the study of $\mathrm{Ng}$ et al. (2019) and Roy et al. (2018). As a plausible explanation, the SRT devices have no strong penetration enough on getting close to shoppers in the brick-and-mortar retail stores, and Malaysia is initially developing SRT ( $\mathrm{Ng}$ et al., 2019). The low usefulness of SRT also reduces the propensity of using SRT, and it is contrary to the study of Roy et al. (2018) and Kim et al. (2016). To elaborate, SRT may impress the Malaysian customers with low utilitarian value since the low penetration rate. Increasing the number of SRT is necessary to strengthen the accessibility of SRT in brick-and-mortar stores. This step could enhance the propensity of customers to approach SRT. However, the current study is in line with the study of Liang et al., (2019), Roy et al., (2018), Li, (2017) and Kaushik and Rahman (2015), in which the perceived ease of use had positive and significant influence attitudes. The SRT users determine SRT devices to have provided a highly friendly user interface that can keep the user attention towards SRT, no matter whether they were new or regular ones. Likewise, the significant effect of perceived enjoyment on attitudes towards SRT has confirmed the study of Choi and Kim, (2016), Kim et al., (2016), Li et al., (2017) and Ng et al., (2019). SRT not only provides utilitarian values but also generates fun and entertaining process shopping experience among offline shoppers. Hence, the consumers got a delightful shopping journey to keep the positive attitudes towards SRT. In integrating SRT into the shopping process, retailers should concern the design and layout of SRT because streamlined SRT will meaningly reduce the SRT learning curve by customers and higher the propensity of approaching SRT in the brick-and-mortar stores. Although the result indicated that perceived risk negatively influences attitudes towards SRT, the relationship was not supported, contrary to the study of Kasilingam (2017) and Kim et al. (2016). The current study acquired around $80.59 \%$ of respondents who hold at least undergraduate education background. This implies most respondents can interpret and digest the new SRT information. Hence, the researchers can interpret this message as the more knowledge consumers attain, the less risk they perceive in approaching SRT. On the contrary, the study presented a significant relationship between attitudes and behavioural intentions towards SRT. The result has complied with the study of Liang et al. (2019), Roy et al. (2018), Kim et al., (2016) as well as Kaushik and Rahman (2015). The positive attitudes bring optimism and constructive thinking towards SRT and allow approaching SRT devices easier. 
Therefore, good attitudes have a high propensity to create positive behavioural intentions towards SRT. Retailers could cultivate usage awareness to educate customers regarding the benefits and knowledge of using SRT in stores.

\section{Conclusions}

The study is important to contribute to the SRT literature. The results showed that customers' behavioural intentions were significantly influenced by perceived ease of use and enjoyment as the local marketplace is initially building the ecosystem of SRT. Hence, Malaysian customers are not aware of the technology's usability. These findings provide several implications. Firstly, retailers could present SRT in the way of pleasing the customer experience in using SRT. Of course, customers enjoy their shopping in brick-and-mortar stores because they can interact with both technology and people. Secondly, the good way to encourage customer acceptance towards SRT is reducing learning effort among customers. It is reasonable to design the SRT to get customers to become skilful as soon as possible. The learning costs reduce the acceptance rate increase. Thirdly, retailers should create a good awareness of the state of mind among customers. Despite the relationship among perceived risk, attitudes, and behavioural intentions was insignificant, customers still have a negative feeling towards SRT as such technology exerts uncertain elements in their mind. Fourthly, SRT is supposed to accustom in-store shopping behaviour. Therefore, increasing the ways of SRT can convince customers to accept SRT when shopping inside the brick-and-mortar store.

The researchers suggest several limitations that can affect further investigations in future. Although perceived usefulness is insignificant in influencing attitudes, future research can be conducted as the SRT penetration rate is higher than now. This study involved respondents with higher education backgrounds. Future research could survey various kinds of customers to generalise the study of SRT in Malaysia. The prevalence of SRT does not only depend on customers' themselves. The future recommendation should involve investigating the environment and product factors to provide more insightful conclusions. Security issues are to be concerned by many people since their daily lives are gradually penetrated by data and information systems.

\section{References}

Adapa, S., Fazal-e-Hasan, S. M., Makam, S. B., Azeem, M. M., \& Mortimer, G. (2020). Examining the antecedents and consequences of perceived shopping value through smart retail technology. Journal of Retailing and Consumer Services, 52, 101901.

Ajzen, I., \& Fishbein, M. (1980). Understanding attitudes and predicting social behaviour. Englewood Cliffs, NJ: Prentice Hall.

Bashir, I. \& Madhavaiah, C. (2017). "Consumer attitude and behavioural intention towards Internet banking adoption in India." Journal of Indian Business Research, 7(1), 67-102.

Bonetti, F., Warnaby, G., \& Quinn, L. (2018). Augmented reality and virtual reality in physical and online retailing: A review, synthesis and research agenda. Augmented reality and virtual reality, 119-132.

Cakır, R., \& Solak, E. (2015). Attitude of Turkish EFL Learners towards e-Learning through Tam Model. Social and Behavioral Sciences, 176, $596-601$.

Chang, Y. W., \& Chen, J. (2021). What motivates customers to shop in smart shops? The impacts of smart technology and technology readiness. Journal of Retailing and Consumer Services, 58, 102325.

Choi, J., \& Kim, S. (2016). Is the smartwatch an IT product or a fashion product? A study on factors affecting the intention to use smartwatches. Computers in Human Behavior, 63, 777-786.

Davis, F. D. (1989). Perceived usefulness, perceived ease of use, and user acceptance of information technology. MIS Quarterly, 13, 319-340.

Dickinger, A., Arami, M., \& Meyer, D. (2008). The role of perceived enjoyment and social norm in the adoption of technology with network externalities. European Journal of Information Systems, 17(1), 4-11.

Featherman, M. S., \& Pavlou, P. A. (2003). Predicting e-services adoption: a perceived risk facets perspective. International Journal of Human-Computer Studies, 59 (4), 451-474.

Fornell, C., \& Larcker, D.F. (1981). Evaluating structural equation models with unobservable variables and measurement error. Journal of Marketing Research, 18(1), 39-50.

Gao, L., \& Bai, X. (2014). A unified perspective on the factors influencing consumer acceptance of internet of things technology. Asia Pacific Journal of Marketing and Logistics, 26(2), 211-231.

Hair, J.F., Jr, Matthews, L.M., Matthews, R.L. \& Sarstedt, M. (2017). PLS-SEM or CB-SEM: updated guidelines on which method to use. International Journal of Multivariate Data Analysis, 2(1), 107-123.

IHS Technology. (2016, March). IoT platforms: enabling the Internet of Things. [PDF document].

Ismail, I. (2019, October 14). 2020 Budget: A boost for Malaysia's tech industry. New Straits Times.

Kasilingam, D. L. (2020). Understanding the attitude and intention to use smartphone chatbots for shopping. Technology in Society, 62, 101280.

Kaushik, A. K. \& Rahman, Z. (2015). An alternative model of self-service retail technology adoption. Journal of Services Marketing, 29(5), 406-420.

Kazancoglu, I., \& Yarimoglu, E. K. (2017). How food retailing changed in Turkey: spread of self-service technologies. British Food Journal, 120(2), 290-308. 
Kim, H.-Y., Lee, J. Y., Mun, J., \& Johnson, K.K. (2017). Consumer adoption of smart in-store technology: Assessing the predictive value of attitude versus beliefs in the technology acceptance model. International Journal of Fashion Design, Technology and Education, 10, 26-36.

Kock, N., \& Hadaya, P. (2018). Minimum sample size estimation in PLS-SEM: The inverse square root and gamma-exponential methods. Information Systems Journal, 28(1), 227-261.

Lam, L. W. (2012). Impact of competitiveness on salespeople's commitment and performance. Journal of Business Research, 65(9), 1328-1334.

Li, R., Chung, T. L., \& Fiore, M. (2017). Factors affecting current users' attitude towards e-auctions in China: An extended TAM study. Journal of Retailing and Consumer Services, 34, 19-29.

Liang, Y.L., Lee, S.H., \& Workman J.E. (2019). Implementation of Artificial Intelligence in Fashion: Are Consumers Ready? Clothing and Textiles Research Journal, 38(1), 3-18.

Liu, Y., Mezei, J., Kostakos, V., \& Li, H. (2017). Applying configurational analysis to IS behavioural research: a methodological alternative for modelling combinatorial complexities. Information Systems Journal, 27(1), 59-89.

Malaysia Smart City Framework (MSCF). (2021). The Malaysian Administrative Modernisation and Management Planning Unit. https://malaysia.gov.my/portal/content/30947

Newman, C. L., Wachter, K., \& White, A. (2018). Bricks or clicks? Understanding consumer usage of retail mobile apps. Journal of Services marketing, 32(2), 211-222.

Ng, S. I., Ho, J. A., Lim, X., J., Chong, K. L. \& Latiff, K. (2019). Mirror, mirror on the wall, are we ready for Gen-Z in marketplace? A study of smart retailing technology in Malaysia. Young Consumers, 22(1), 68-89.

Pantano, E., Rese, A., \& Baier, D. (2017). Enhancing the online decision-making process by using augmented reality: A two country comparison of youth markets. Journal of Retailing and Consumer Services, 38, 81-95.

Pantano, E., \& Viassone, M. (2014). Demand pull and technology push perspective in technology-based innovations for the points of sale: The retailers evaluation. Journal of Retailing and Consumer Services, 21(1), 43-47.

Park, J. S., Ha, S., \& Jeong, S. W. (2020). Consumer acceptance of self-service technologies in fashion retail stores. Journal of Fashion Marketing and Management: An International Journal, 25(2), 371-388.

Patil, P., Tamilmani, K., Rana, N. P., \& Raghavan, V. (2020). Understanding consumer adoption of mobile payment in India: Extending Meta-UTAUT model with personal innovativeness, anxiety, trust, and grievance redressal. International Journal of Information Management, 54, 102144

Pillai, R., Sivathanu, B., \& Dwivedi, Y. K. (2020). Shopping intention at AI-powered automated retail stores (AIPARS). Journal of Retailing and Consumer Services, 57, 102207.

PWC. (2019). It's time for a consumer-centred metric: introducing 'return on experience.' [PDF document].

Rahman, M., Ismail, I., \& Bahri, S. (2020). Analysing consumer adoption of cashless payment in Malaysia. Digital Business, 1(1), 100004.

Rasoolimanesh, M. S., Suhaida M. N., \& Jaafar, M. (2018). Positive and Negative Perceptions of Residents Toward Tourism Development: Formative or Reflective. Springer Link.

Roy, S. K., Balaji, M. S., \& Nguyen, B. (2020). Consumer-computer interaction and in-store smart technology (IST) in the retail industry: the role of motivation, opportunity, and ability. Journal of Marketing Management, 36(3-4), 299-333.

Roy, S. K., Balaji, M.S., Quasi, A., \& Quaddus, M. (2018). Predictors of customer acceptance of and resistance to smart technologies in the retail sector. Journal of Retailing and Consumer Services, 42, 147-160.

Roy, S. K., Balaji, M. S., Sadeque, S., Nguyen, B., \& Melewar, T. C. (2017). Constituents and consequences of smart customer experience in retailing. Technological Forecasting and Social Change, 124, 257-270.

Roy, S. K., Singh, G., \& Shabnam, S. (2021). Modelling Customer Engagement Behaviour in Smart Retailing. Australasian Journal of Information Systems, 25.

Salihu, A., Metin, H., Hajrizi, E., \& Ahmeti, M. (2019). The effect of security and ease of use on reducing the problems/deficiencies of Electronic Banking Services. IFAC-PapersOnLine, 52(25), 159-163.

Straub, E. T., (2009). Understanding Technology Adoption: Theory and Future Directions for Informal Learning. Review of Educational Research, 79(2), 625-649.

Wang, W. T., \& Li, H. M. (2012). Factors influencing mobile services adoption: a brand-equity perspective. Internet Research, 22(2), 142-179.

Wünderlich, N. V., Heinonen, K., Ostrom, A. L., Patricio, L., Sousa, R., Voss, C., \& Lemmink, J. G. (2015). "Futurising" smart service: implications for service researchers and managers. Journal of Services Marketing, 29(6/7), $442-447$.

Wu, L.-H., Wu, L.-C., \& Chang, S.-C. (2016). Exploring consumers' intention to accept smartwatch. Computers in Human Behavior, 64, 383-392.

Yan, L. Y., Tan, G. W. H., Loh, X. M., Hew, J. J., \& Ooi, K. B. (2021). QR code and mobile payment: The disruptive forces in retail. Journal of Retailing and Consumer Services, 58, 102300.

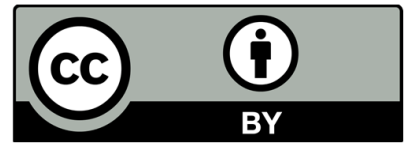

(C) 2022 by the authors; licensee Growing Science, Canada. This is an open access article distributed under the terms and conditions of the Creative Commons Attribution (CC-BY) license (http://creativecommons.org/licenses/by/4.0/). 